\title{
The a7 nicotinic acetylcholine receptor agonist, GTS-21, attenuates hyperoxia- induced acute inflammatory lung injury by alleviating the accumulation of HMGB1 in the airways and the circulation
}

Ravikumar A. Sitapara ${ }^{1 \dagger}$, Alex G. Gauthier ${ }^{1 \dagger}$, Sergio I. Valdés-Ferrer ${ }^{2}$, Mosi Lin $^{1} \mathbb{D}^{0}$, Vivek Patel $^{1}$, Mao Wang ${ }^{1}$, Ashley T. Martino', Jeanette C. Perron ${ }^{1}$, Charles R. Ashby $\mathrm{Jr}^{1}$, Kevin J. Tracey ${ }^{2}$, Valentin A. Pavlov ${ }^{2 *}$ and Lin L. Mantell ${ }^{1,2^{*}}$

\begin{abstract} and circulation, and consequently attenuates inflammatory lung injury. $4 \mathrm{mg} / \mathrm{kg}$, i.p.) or the control vehicle, saline.

(Continued on next page)

The Commentary article for this Short Report Article is https://doi.org/10. 1186/s10020-020-00184-0.

*Correspondence: vpavlov@northwell.edu; mantell@stjohns.edu; Imantell@northwell.edu

${ }^{+}$Ravikumar A. Sitapara and Alex G. Gauthier contributed equally to this work.

${ }^{2}$ Feinstein Institutes for Medical Research, Northwell Health System, 350

Community Drive, Manhasset, New York 11030, USA

'Department of Pharmaceutical Sciences, St, College of Pharmacy and Health Sciences, St. John's University College of Pharmacy and Health Sciences, St. Albert Hall, 8000 Utopia Parkway, Queens, New York 11439, USA
\end{abstract}

Background: Oxygen therapy, using supraphysiological concentrations of oxygen (hyperoxia), is routinely administered to patients who require respiratory support including mechanical ventilation (MV). However, prolonged exposure to hyperoxia results in acute lung injury (ALI) and accumulation of high mobility group box 1 (HMGB1) in the airways. We previously showed that airway HMGB1 mediates hyperoxia-induced lung injury in a mouse model of ALI. Cholinergic signaling through the a7 nicotinic acetylcholine receptor (a7nAChR) attenuates several inflammatory conditions. The aim of this study was to determine whether 3-(2,4 dimethoxy-benzylidene)-anabaseine dihydrochloride, GTS-21, an a7nAChR partial agonist, inhibits hyperoxia-induced HMGB1 accumulation in the airways

Methods: Mice were exposed to hyperoxia $\left(\geq 99 \% \mathrm{O}_{2}\right)$ for 3 days and treated concurrently with GTS-21 (0.04, 0.4 and

Results: The systemic administration of GTS-21 (4 mg/kg) significantly decreased levels of HMGB1 in the airways and the serum. Moreover, GTS-21 (4 mg/kg) significantly reduced hyperoxia-induced acute inflammatory lung injury, as indicated by the decreased total protein content in the airways, reduced infiltration of inflammatory monocytes/ macrophages and neutrophils into the lung tissue and airways, and improved lung injury histopathology.

(c) The Author(s). 2020 Open Access This article is licensed under a Creative Commons Attribution 4.0 International License, which permits use, sharing, adaptation, distribution and reproduction in any medium or format, as long as you give appropriate credit to the original author(s) and the source, provide a link to the Creative Commons licence, and indicate if changes were made. The images or other third party material in this article are included in the article's Creative Commons licence, unless indicated otherwise in a credit line to the material. If material is not included in the article's Creative Commons licence and your intended use is not permitted by statutory regulation or exceeds the permitted use, you will need to obtain permission directly from the copyright holder. To view a copy of this licence, visit http://creativecommons.org/licenses/by/4.0/. 
(Continued from previous page)

Conclusions: Our results indicate that GTS-21 can attenuate hyperoxia-induced ALI by inhibiting extracellular HMGB1mediated inflammatory responses. This suggests that the a7nAChR represents a potential pharmacological target for the treatment regimen of oxidative inflammatory lung injury in patients receiving oxygen therapy.

Keywords: Hyperoxia, Lung injury, a7nAChR, Vagus nerve, Cholinergic anti-inflammatory pathway, Inflammatory reflex, Sterile inflammation

\section{Introduction}

Patients with hypoxemia and acute respiratory failure frequently require the administration of hyperoxia (inspired content of $\mathrm{O}_{2}>21 \%$ ) (Carvalho 1998; Snider and Rinaldo 1980; Han and Mallampalli 2015). In this context, hyperoxia can become a lifesaving intervention in clinical scenarios as diverse as preterm newborns, adults with respiratory distress, or patients suffering from severe acute respiratory decline, such as patients with COVID-19 (Windhorst et al. 2009; Silversides and Ferguson 2013; Giwa et al. 2020; Guan et al. 2020; Huang et al. 2020). However, prolonged exposure to hyperoxia is associated with oxygen toxicity, due to the excessive production of reactive oxygen species (ROS), which can lead to oxidative stress-mediated acute inflammatory lung injury, known as hyperoxia-induced acute lung injury (HALI) (Kallet and Matthay 2013; Morrow et al. 2007; Matthay and Zimmerman 2005).

This oxidative stress-mediated HALI is characterized by 1) an influx of inflammatory cells, including polymorphonuclear neutrophils (PMNs); 2) enhanced cytokine production; 3) injury and death of pulmonary epithelial and endothelial cells; 4) pulmonary proteinaceous edema; 5) destruction of the alveolar-capillary barrier; and 6) impaired gas exchange, leading to the severe morbidity and mortality in patients on ventilation (Bhandari and Elias 2006; Crapo 1986; Slutsky 1999; van Zoelen et al. 2008). In this context, pro-inflammatory chemokines and cytokines have been implicated in neutrophil recruitment into the lungs (Jiang et al. 2017; Matthay et al. 2012; Belperio et al. 2002; Olson and Ley 2002). However, the specific molecular mechanisms underlying cytokine-mediated HALI remain to be elucidated. Clinically, there are no efficacious treatments that significantly reduce the inflammatory lung injury in patients receiving oxygen therapy.

Previously, we have shown that prolonged exposure to hyperoxia induces the accumulation of high mobility group box-1 protein (HMGB1) in mouse airways (Entezari et al. 2014). The mechanistic role of HMGB1 in oxidative stress-induced ALI is incompletely understood; extracellular HMGB1, either actively secreted by immune cells or passively released by necrotic cells, has been implicated in the pathophysiology of a variety of inflammatory conditions (Scaffidi et al. 2002; Yang et al.
2001), such as sepsis and rheumatoid arthritis (Andersson et al. 2000; Taniguchi et al. 2003; Wang et al. 1999; Wang et al. 2004). The inactivation of HMGB1 with specific anti-HMGB1 antibodies increased the survival of animals with severe polymicrobial sepsis, reduced high tidal volume ventilation-induced lung injury, and diminished endotoxin and hemorrhageinduced increases in pulmonary levels of inflammatory cytokines (Abraham et al. 2000; Lutz and Stetkiewicz 2004; Ogawa et al. 2006; Ueno et al. 2004). In addition, an increase in the levels of HMGB1 in the plasma and lung epithelial-lining fluids has been reported in patients with ALI (Kolliputi et al. 2010; Misharin et al. 2013). Extracellular HMGB1, a potent pro-inflammatory mediator (Wang et al. 1999), can initiate an inflammatory response, facilitating the progression of sepsis and ALI (Entezari et al. 2014; Abraham et al. 2000; Kolliputi et al. 2010; Crapo et al. 1982; Liu et al. 2008). Currently, the role of HMGB1 in oxidative stress-induced ALI remains to be elucidated. We have previously shown a significant correlation between airway HMGB1 levels and oxidative lung injury induced by hyperoxia (Entezari et al. 2014). The exposure of mice to hyperoxia $\left(\geq 99 \% \mathrm{O}_{2}\right)$ results in an increased accumulation of HMGB1 in the mouse airways and the administration of anti-HMGB1 antibodies significantly reduced the severity of HALI (Entezari et al. 2014). These results indicate that the high levels of airway HMGB1 play a critical role in lung injury induced by oxidative stress under hyperoxic conditions. Therefore, targeting the accumulation of airway HMGB1 may be of benefit in the treatments of patients with HALI.

The activation of $\alpha 7$ nicotinic acetylcholine receptors ( $\alpha 7 \mathrm{nAChRs}$ ) plays a critical role in mediating the vagus nerve-based inflammatory reflex and specifically its efferent arm, termed the cholinergic anti-inflammatory pathway (Wang et al. 2003; Borovikova et al. 2000). Its activation results in decreased translocation of HMGB1 from the nucleus to the cytoplasm, with subsequent release into the extracellular milieu (Wang et al. 2003; Brewer et al. 1996; Bustin 2001; de Jonge and Ulloa 2007; Pavlov et al. 2007). Lung cells express high levels of $\alpha 7 \mathrm{nAChR}$, which could be targeted to reduce the accumulation of extracellular HMGB1 (Bustin 2001; Pavlov et al. 2007; Calogero et al. 1999). GTS-21, a partial agonist of $\alpha 7 \mathrm{nAChR}$ (Chastre and Fagon 2002; Cook et al. 1998), has been previously used therapeutically for 
experimental sepsis and in other preclinical conditions (Pavlov et al. 2007; Kang et al. 2014; Tarnawski et al. 2018; Mavropoulos et al. 2017). GTS-21 has been used in human studies and has a favorable safety profile at doses up to 450 mg/day (Kitagawa et al. 2003; Kox et al. 2011). The aims of this study were to determine the effects of GTS-21 on (a) the accumulation of extracellular HMGB1 in the animals subjected to prolonged exposure to hyperoxia, (b) attenuating hyperoxia-induced lung injury and (c) hyperoxia-induced pulmonary pro-inflammatory responses, especially the infiltration of inflammatory leukocytes into the airways and lung tissues.

\section{Materials and methods Special reagents}

GTS-21 was obtained from Abcam (Cambridge, MA, USA). The $\mathrm{pH}$ of the GTS-21 solution was adjusted to 7 before intra-peritoneal injection in mice. $0.9 \%$ normal saline solution was used as the control vehicle.

\section{Animal studies}

C57BL/6 mice (male, 8 to 12 weeks old; The Jackson Laboratory, Bar Harbor, ME, USA) were used in this study, in accordance with the Institutional Animal Care and Use Committees of St. John's University. The mice were housed in a specific pathogen-free environment maintained at $22{ }^{\circ} \mathrm{C}$ in $\approx 50 \%$ relative humidity with a 12 -h light/dark cycle. All mice had ad libitum access to standard rodent food and water. Mice were exposed to hyperoxia as previously described (Patel et al. 2013). Briefly, animals were placed in micro isolator cages (Allentown Caging Equipment, Allentown, NJ, USA) that were kept in a Plexiglas chamber (BioSpherix, Lacona, NY, USA) and exposed to $\geq 99 \% \mathrm{O}_{2}$ or remained in room air for 72 h. Mice exposed to hyperoxia were randomized to receive either intraperitoneally administered GTS-21 (0.04, 0.4 and $4 \mathrm{mg} / \mathrm{kg}$ ) or the control vehicle, saline, every $8 \mathrm{~h}$, starting $32 \mathrm{~h}$ after the onset of hyperoxic exposure. At the end of hyperoxic exposure, mice were euthanized with intraperitoneal sodium pentobarbital $(120 \mathrm{mg} / \mathrm{kg})$ to obtain bronchoalveolar lavage (BAL) fluid samples or lung tissues, as described below, for further analysis.

\section{Bronchoalveolar lavage fluids and serum collection}

Murine BAL fluid containing proteinaceous debris and cells was obtained as previously described (Patel et al. 2013; Sitapara et al. 2014). Briefly, mice were euthanized by an intraperitoneal injection of sodium pentobarbital $(120 \mathrm{mg} / \mathrm{kg})$. Following a 1 - to 2 -cm incision made on the neck, the trachea was dissected and a 20-gauge $\times$ 1.25 -in. intravenous catheter was inserted caudally into the lumen of the exposed trachea. The lungs were gently lavaged twice with $1 \mathrm{~mL}$ of a sterile, nonpyrogenic phosphate-buffered saline (PBS) solution (Mediatech,
Herndon, VA, USA). The BAL samples were centrifuged at $4{ }^{\circ} \mathrm{C}$ at $3200 \mathrm{x} \mathrm{g}$ and the resultant supernatants were stored at $-80^{\circ} \mathrm{C}$ and pellets used for cell content analysis. For serum collection, whole blood was collected by cardiac puncture and allowed to coagulate for $30 \mathrm{~min}$ at room temperature. Next, samples were centrifuged at $2000 \mathrm{x} \mathrm{g}$ for $10 \mathrm{~min}$ at $4{ }^{\circ} \mathrm{C}$ and the resulting supernatant was stored as serum samples. Proteins in normalized volumes of BAL and serum samples were separated by SDS-PAGE and HMGB1 concentrations were determined by Western blot analysis as described below. Total BAL protein content was analyzed by bicinchoninic acid (BCA) assay in BAL samples. For cell content analysis in BAL samples, cell pellets were subjected to red blood cell lysis. Next, differential cell analysis was performed by depositing a monolayer of cells onto a cover slip using a Shandon Cytospin 2 centrifuge (Marshall Scientific, Hampton, NH) and then stained with Hema 3 solution kit (Fisher Scientific, Hampton, NH) per the manufacturer's instructions or by flow cytometry analysis as described below.

\section{Measurement of HMGB1}

The concentrations of HMGB1 in BAL samples were determined using immunoblotting analysis with an antiHMGB1 antibody, as previously described (Wang et al. 1999). In brief, samples were separated first on SDS-PAGE. Next, the proteins were electrotransferred to a polyvinyledene difluoride membrane, and blocked with 5\% nonfat dry milk in Tris-buffered saline with $0.1 \%$ Tween-20 (TBST). The membrane was incubated with anti-HMGB1 (1:1000), washed with TBST, followed by incubation with a goat anti-rabbit horseradish peroxidase-coupled secondary antibody $(1: 10,000)$ (BioRad, Hercules, CA). After washing, antibody binding was detected using Enhanced Chemiluminescence Plus Western blotting detection reagents (Amersham Pharmacia Biotech, Piscataway, NJ). Western blots were scanned with a UVP Biospectrum 600 Imaging System (Vision Works LS, Upland, CA), and the band intensities were quantified using Image J analysis software version 2.0.0 (Works LS, Upland, CA).

\section{Histopathology}

Histopathological evaluation was conducted in paraffinembedded tissues as previously described (Entezari et al. 2014). Prior to removal from the animal, the lungs were instilled with buffered formalin solution through a 20gauge angiocatheter placed in the trachea. The lungs were then immersed in buffered formalin overnight and processed for conventional paraffin histology. The sections were stained with hematoxylin and eosin and examined with an Evos XL core microscope (Life Technologies, Grand Island, NY). Lung injury scores were 
performed by three blinded independent investigators using the scoring criteria described in Szarka et al. 1997.

\section{Immunohistochemistry}

Macrophage/monocyte staining was performed on cryosectioned lung tissue as previously described (Martino et al. 2011). Briefly, before removal from the animal, the lungs were rinsed with PBS and then instilled with 30\% sucrose solution through a 20-gauge angiocatheter placed in the trachea. The lungs were frozen in an optimal cutting temperature (OCT) solution. The sections from lung tissue blocks cryopreserved in OCT were mounted on Superfrost plus slides. The sections were fixed for $10 \mathrm{~min}$ at room temperature (RT) in acetone and then air-dried for $15 \mathrm{~min}$. An HRP immunohistochemistry staining protocol for CD11b was used with hematoxylin counter stain and mounted with Vectamount AQ aqueous mounting media (Vector Labs, Burlingame, CA). In brief, the sections were blocked (5\% goat serum in PBS) for $30 \mathrm{~min}$ at RT, followed by PBS rinse. Biotinylated CD11b primary antibody (Thermo Scientific, Waltham, MA) was added at a 1:100 dilution in PBS with $1 \%$ goat serum for $60 \mathrm{~min}$ at RT, or with anti-HMGB1 antibody (Cell Signaling Technologies, Danvers, MA), at a 1:100 dilution overnight at $4{ }^{\circ} \mathrm{C}$, followed by a PBS rinse. Peroxidase was blocked for 10 min at RT with peroxide suppressor (Thermo Scientific). After the PBS rinse, streptavidin-HRP (BD Biosciences, San Jose, CA) was added at a 1:100 diluted in PBS with $1 \%$ goat serum for $30 \mathrm{~min}$ at RT in the dark. Next, slides were stained with a 3,3- diaminobenzidine (DAB) buffer kit and hematoxylin stain (Vector Labs) per the manufacturer's protocol. At least 15 images per slide were captured at 200x magnification using an inverted light microscope. CD11b positive cells were counted manually from captured images. Data were calculated per square centimeter.

\section{Flow Cytometric analysis}

BAL cells were incubated for $10 \mathrm{~min}$ at $4{ }^{\circ} \mathrm{C}$ with an anti-mouse CD16/32 antibody (1:200; Biolegend, San Diego, CA) to block non-specific binding, followed by incubation with a FITC-conjugated anti-mouse CD11b (1:200; Biolegend, San Diego, CA) and an AF 700conjugated anti-mouse CD11c (1:200, Biolegend) antibodies for $30 \mathrm{~min}$ at $4{ }^{\circ} \mathrm{C}$. Data were collected on a BD LSR Fortessa flow cytometer using FACSDiva software (Becton Dickinson, Mountain View, CA) and analyzed using FlowJo software (Tree Star, San Carlos, CA). A range of 20,000-50,000 cells was analyzed per sample. The initial gating eliminated debris and red blood cells. Next, consecutive gates, were set to identify $\mathrm{CD}_{11 \mathrm{c}^{+}}$and $\mathrm{CD} 11 \mathrm{~b}^{+}$cells, as previously described (Swirski et al. 2009; Valdés-Ferrer et al. 2013).
The relative expression of $\mathrm{CD} 11 \mathrm{c}$ was used to distinguish CD11c-positive alveolar macrophages $\left(\mathrm{CD} 11 \mathrm{c}^{+}\right.$, $\mathrm{CD}_{11 \mathrm{~b}^{+}}$) and CD11c-negative infiltrated cells $\left(\mathrm{CD} 11 \mathrm{c}^{\text {neg }}, \mathrm{CD}_{11 \mathrm{~b}^{+}}\right)$. Fluorescence minus one (FMO) controls were used for proper gating.

\section{Statistical analysis}

All the data was analyzed using GraphPad Prism statistical software. The results are presented as the mean \pm SEM. The data were analyzed for statistical significance according to unpaired t-test, and analysis of variance (ANOVA) with Dunnett's post hoc analysis. The survival data were analyzed using the Kaplan-Meier analysis. The a priori $p$ value was $p<0.05$.

\section{Results and discussion}

Prolonged exposure to hyperoxia induces the accumulation of HMGB1 in the airways of the exposed subjects, which can be a critical contributor to HALI (Entezari et al. 2014; Abraham et al. 2000; Ueno et al. 2004; Wang et al. 2019). Similar to other types of acute lung injury, HALI is characterized by the injury/damage of alveolar epithelial cells and pulmonary endothelial cells. The resulting impairment of the alveolar barrier can be assessed by measuring the protein content released into the airways and the presence of elevated leukocyte counts (Doerschuk 2000; Barnett and Ware 2011; Mokra and Kosutova 2015; Pittet et al. 1997). As shown in Fig. 1a, hyperoxia-induced inflammatory lung injury was characterized by increased protein leakage into the airways (Entezari et al. 2014), and $4 \mathrm{mg} / \mathrm{kg}$ i.p. of GTS-21 partially rescued mice from hyperoxia-induced pulmonary accumulation of proteins in the airways $(1687 \mu \mathrm{g} \pm$ $242 \mu \mathrm{g}$ of protein $/ \mathrm{mL}$, versus $99 \% \mathrm{O}_{2}$ control vehicle $2618 \pm 298 \mu \mathrm{g}$ of protein $/ \mathrm{mL}, p<0.05)$. Similarly, $4 \mathrm{mg} /$ kg i.p. of GTS-21 significantly attenuated hyperoxiainduced inflammatory lung injury (Fig. 1b and c). As we have previously reported, there is a significant positive correlation between the hyperoxia-induced inflammatory lung injury, including the infiltration of neutrophils, and the severity of HALI in mice exposed to hyperoxia (Entezari et al. 2014). This damage is also observed in mice exposed to hyperoxia and subjected to control vehicle treatment, as compared to mice that remained in room air (Fig. $1 \mathrm{~b}$ and c, $1.88 \pm 0.29$ versus $0.352 \pm 0.07$ of the room air control, $p<0.05)$. Hyperoxia-induced acute inflammatory lung injury was attenuated by the administration of $4 \mathrm{mg} / \mathrm{kg}$ i.p. of GTS-21 (Fig. 1b and c, $1.26 \pm$ 0.16 score versus control vehicle $1.88 \pm 0.29$ score, $p<$ $0.05)$. Hyperoxia induces excessive production of ROS, causing oxidative stress-mediated ALI (Bhandari and Elias 2006; Zhang et al. 2003). The increased infiltration of ROS-releasing neutrophils can result in further oxidative stress-induced cell damage and lung injury (Steer 


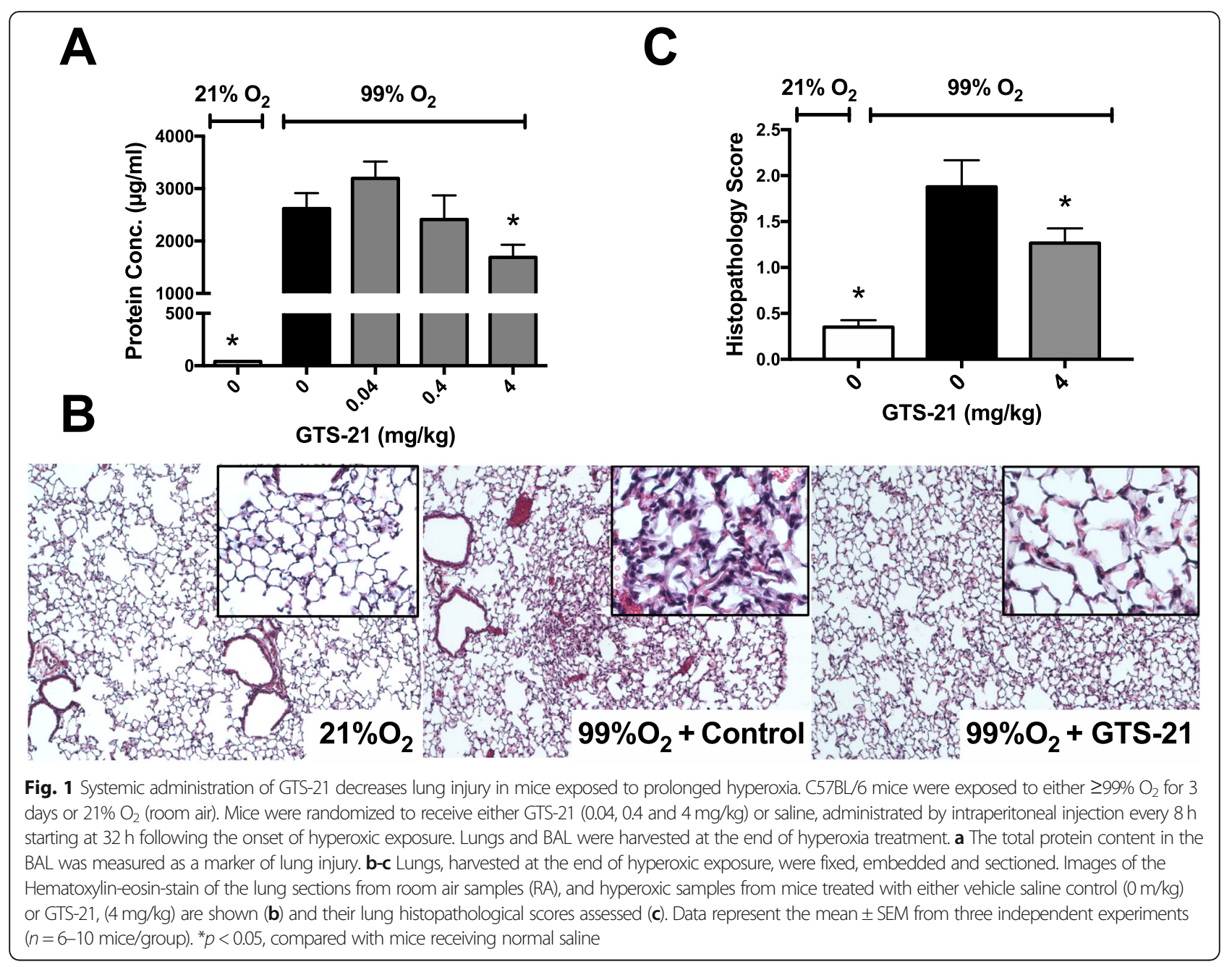

et al. 2013; Han et al. 2018). Oxidative stress has also been implicated in LPS-induced ALI, which produces an increase in neutrophil recruitment to the lung, pulmonary cell apoptosis and an increase in the airway levels of HMGB1, TNF $\alpha$ and polymorphonuclear cells (Xie et al. 2012).

Extracellular HMGB1, either actively secreted by immune cells or passively released by necrotic cells, has been implicated in the pathophysiology of a variety of inflammatory diseases (Scaffidi et al. 2002; Yang et al. 2001; Bonaldi et al. 2003). Airway HMGB1 induces significant pro-inflammatory responses in the lungs of mice exposed to hyperoxia (Entezari et al. 2014). The inactivation of HMGB1 with specific, neutralizing anti-HMGB1 antibodies significantly decreases inflammatory lung injury and increases the survival of animals in several mouse models of ALI (Entezari et al. 2014; Abraham et al. 2000; Wang et al. 2019). The inactivation of HMGB1 with a neutralizing antibody or the activation of $\alpha 7 \mathrm{nAChR}$ with acetylcholine or GTS-21 inhibits the receptor for advanced glycation end products (RAGE)- mediated endocytosis of extracellular HMGB1 and HMGB1-LPS complexes, resulting in in a decrease in TNF $\alpha$ secretion and cell death in macrophages (Yang et al. 2019). ALI (induced by either polymicrobial sepsis, high tidal volume ventilation, endotoxin, or hemorrhage) is attenuated by the administration of anti-HMGB1 antibodies, which may be a result of decreased proinflammatory responses (Abraham et al. 2000; Lutz and Stetkiewicz 2004; Ogawa et al. 2006; Ueno et al. 2004). Accordingly, this study evaluated the levels of extracellular HMGB1 in both BAL (Fig. 2a) and serum samples (Fig. 2b), obtained from animals exposed to either hyperoxia or remained in room air. Similar to previous observations (Entezari et al. 2014), mice exposed to hyperoxia have significant levels of airway HMGB1 (Fig. 2a) (Entezari et al. 2014). The administration of $4 \mathrm{mg} / \mathrm{kg}$ i.p. of GTS-21 significantly reduced HMGB1 concentration in the airways (Fig. 2a) $(9.38 \pm 1.57$ A.U. versus control vehicle $15.24 \pm 1.8$ A.U., $p<0.05)$. Next, we determined whether HMGB1 perturbation in the lung appears only in the airways. As shown in Fig. 2b, no detectable 


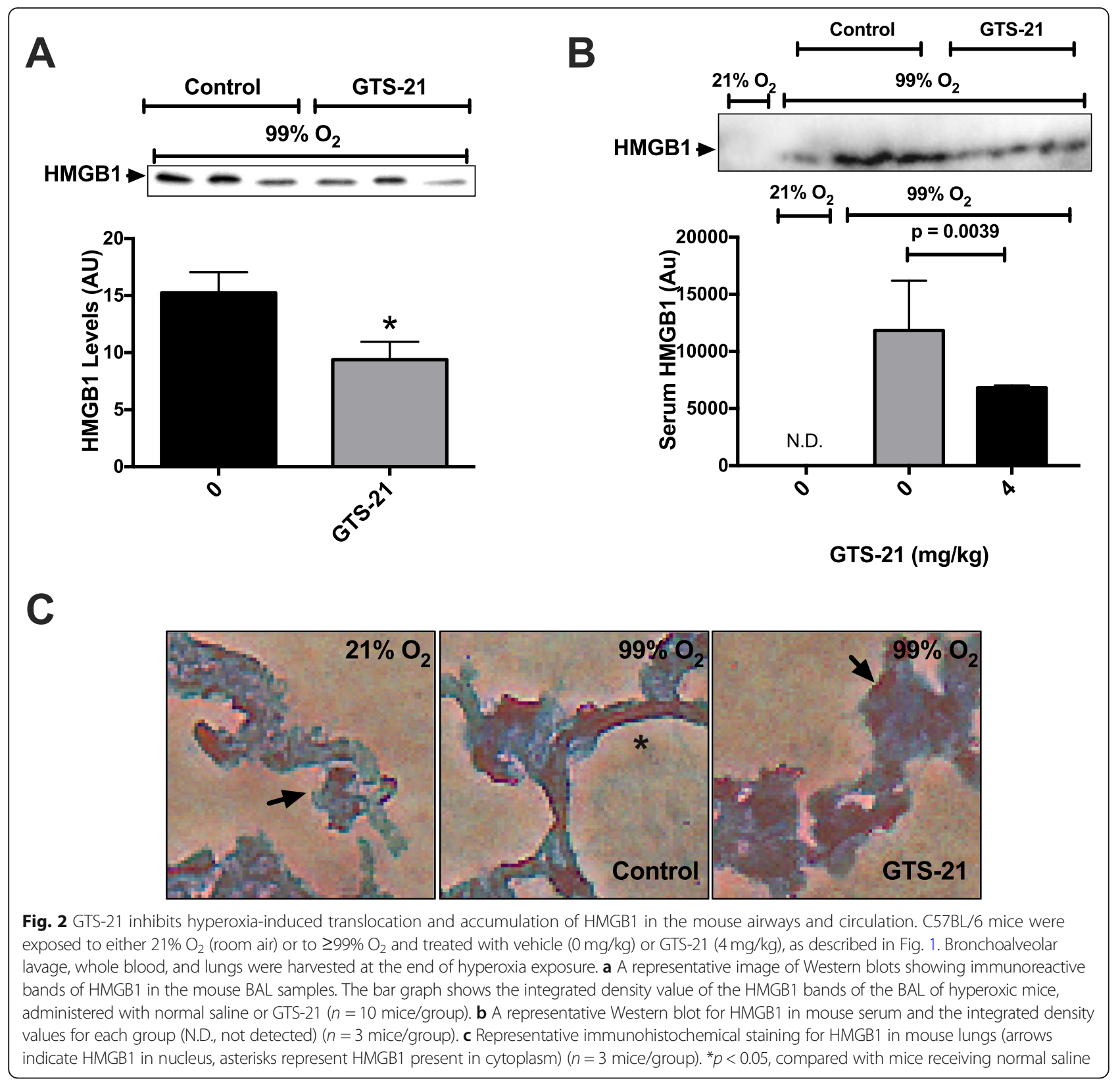

HMGB1 was observed in the circulation, reflecting our previous findings (Entezari et al. 2014). While exposure to hyperoxia for 3 days caused a markedly accumulation of extracellular HMGB1 in the serum, GTS-21 $(4 \mathrm{mg} / \mathrm{kg})$ significantly attenuated this accumulation $\left(0.6 \times 10^{4} \pm\right.$ $0.02 \times 10^{4}$ A.U. versus control vehicle $1.2 \times 10^{4} \pm 0.4 \times$ $10^{4}$ A.U. $\left.p<0.05\right)$. Moreover, immunohistochemical analysis indicated (Fig. 2c) that hyperoxia-induced HMGB1 nuclear-to-cytoplasmic translocation in lung structural cells, as previously reported (Entezari et al. 2014), a critical step required for HMGB1 secretion, was significantly suppressed in GTS-21 (4 mg/kg i.p.) treated mice. We and others have shown that GTS-21 1) inhibits
HMGB1 release from immune cells that were stimulated by hyperoxia (Sitapara et al. 2014) or LPS and 2) decreases levels of serum HMGB1 in a mouse model of endotoxemia (Pavlov et al. 2007; Rosas-Ballina et al. 2009). Taken together, these data suggest that GTS-21 attenuates HALI by significantly reducing the accumulation of extracellular HMGB1, attenuating its inflammatory effects both systematically and in the lung and subsequently ALI in hyperoxia-exposed subjects.

Interestingly, the increase in the levels of extracellular HMGB1 in the airways and serum (Fig. 2) occurred concomitantly with a significant increase in the infiltration of leukocytes into the airways in mice subjected to 


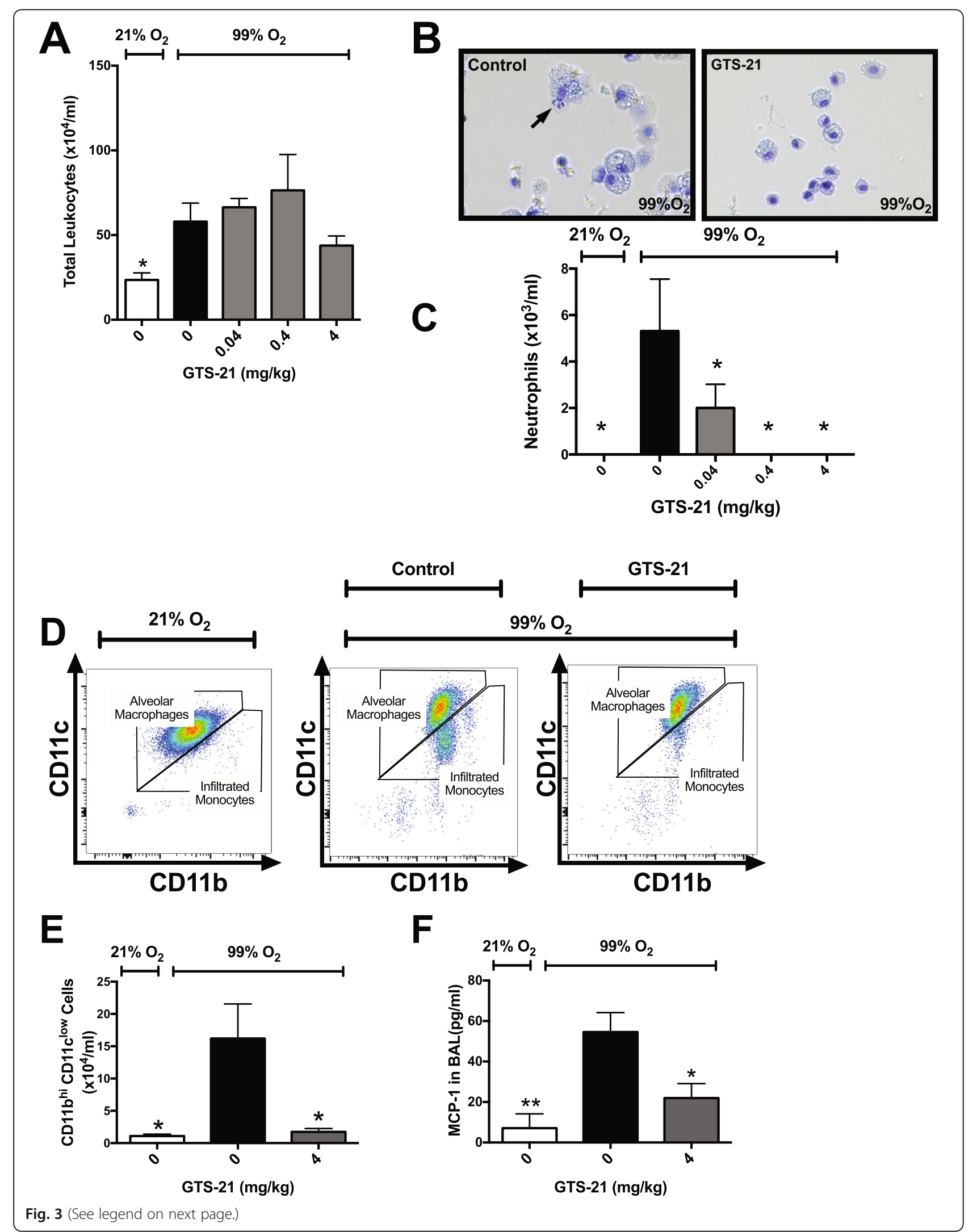


(See figure on previous page.)

Fig. 3 Systemic administration of GTS-21 inhibits infiltration of neutrophils and monocytes into the airways of mice exposed to hyperoxia. C57BL/ 6 mice were exposed to room air $\left(21 \% \mathrm{O}_{2}\right)$ or hyperoxia $\left(\geq 99 \% \mathrm{O}_{2}\right)$ and treated with vehicle $(0 \mathrm{mg} / \mathrm{kg})$ or GTS-21 $(4 \mathrm{mg} / \mathrm{kg})$, as described in Fig. 1 . a The total amount of leukocytes in the BAL were determined by hemocytometer. $\mathbf{b}$ Cells from the BAL samples were analyzed using differential cell staining. Arrows show the presence of neutrophils stained with eosin and methylene blue in BAL samples. c The total number of infiltrated neutrophils in the BAL samples. d-f Cells from BAL were labeled with anti-CD11b and anti-CD11c antibodies and analyzed by flow cytometry (d-e); MCP-1 were analyzed by ELISA (f). $\mathbf{d}$ Representative gating for CD $11 b^{\text {thi }}$ and CD11 $c^{\text {low }}$ cells in the BAL. e The graph is a representative of two independent experiments. $\mathbf{f}$ The bar graph for MCP-1 expression in BAL. Data is represented as the mean \pm SEM ( $n=2-6$ per group). ${ }^{*} p<0.05$, compared with mice receiving normal saline

prolonged exposure to hyperoxia (Fig. 3a). Similar to other inflammatory diseases, leukocyte infiltration plays a pivotal role in facilitating hyperoxia-induced inflammatory lung injury (Kang et al. 2014; Wang et al. 2019; Grommes and Soehnlein 2011). Although GTS-21 did not significantly reduce the infiltration of leukocytes into the airways, a small number of leukocytes were present in the airways of mice treated with $4 \mathrm{mg} / \mathrm{kg}$ i.p. of GTS21 (Fig. 3a). The increased levels of airway HMGB1 have been reported to exacerbate ALI due to neutrophilic inflammation (Andersson and Tracey 2011). Extracellular HMGB1 produces inflammation due to its interaction with certain chemokine and cytokine receptors (Entezari et al. 2014; Wang et al. 1999; Abraham et al. 2000; Entezari et al. 2012). We and others have reported that the intra-tracheal administration of HMGB1 induces a significant inflammatory response characterized by the infiltration of neutrophils into the lungs of mice (Entezari et al. 2014; Abraham et al. 2000). In addition, in a mouse model of HALI, we have shown that HMGB1 accumulates in the airways prior to infiltration of neutrophils into the airways and the onset of lung injury (Entezari et al. 2014). In the present study, the attenuated extracellular HMGB1 accumulation in the airways and serum of mice treated with $4 \mathrm{mg} / \mathrm{kg}$ i.p. of GTS-21 was not accompanied by a significant reduction in total leukocyte

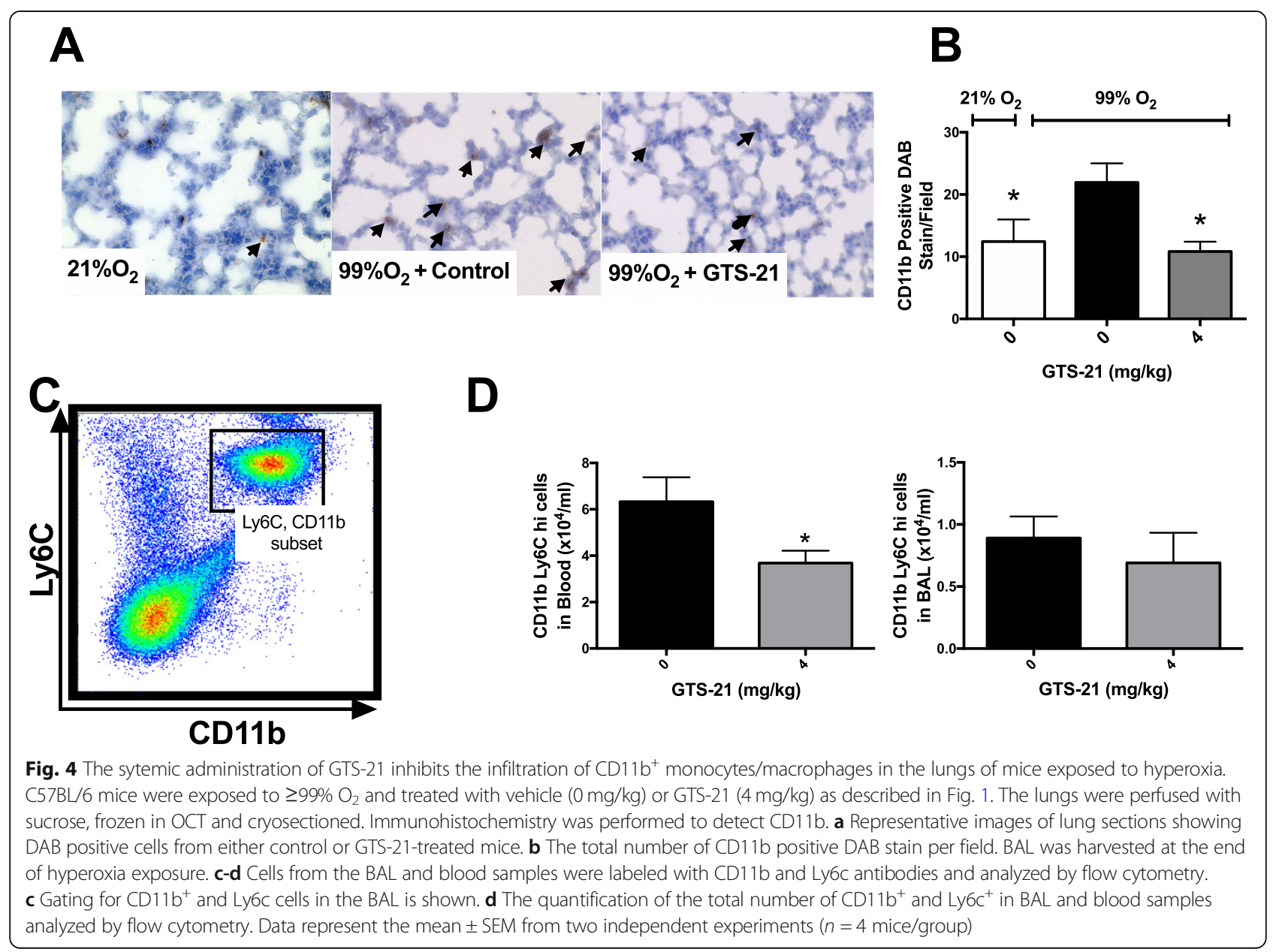




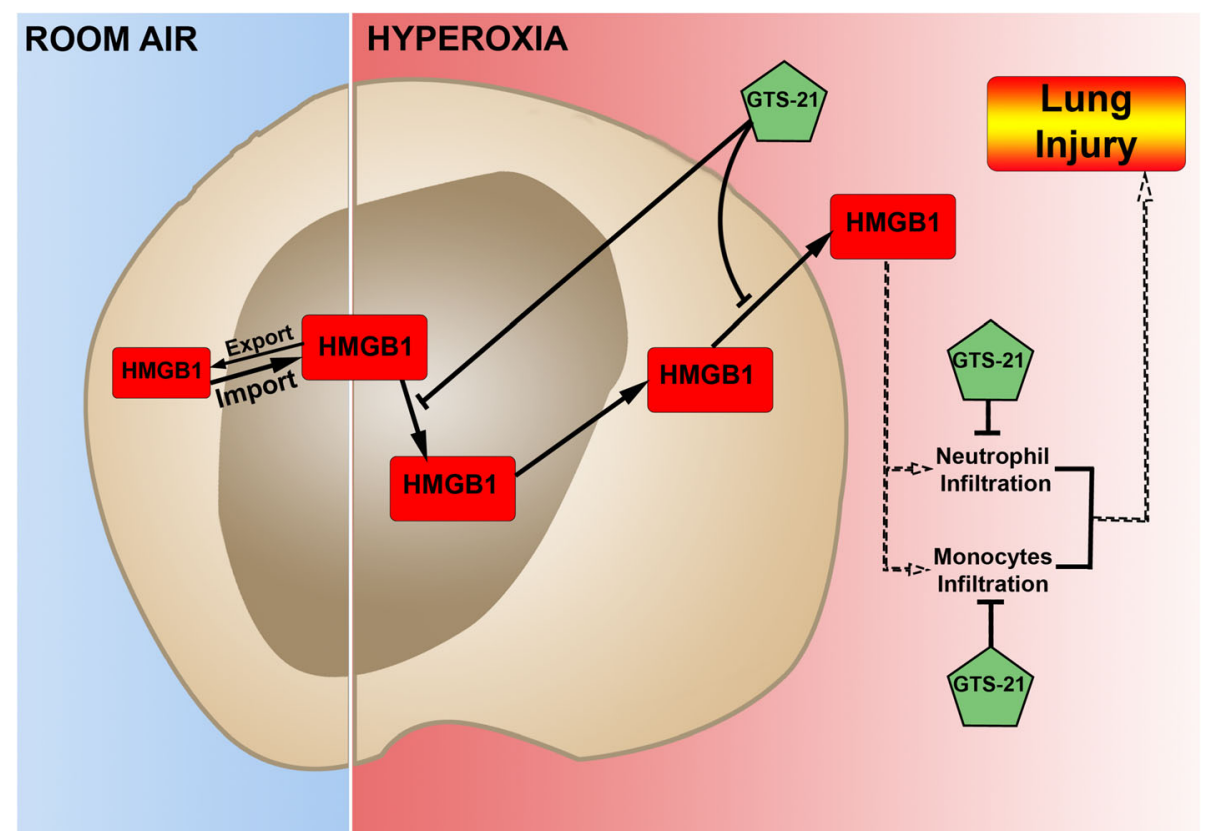

Fig. 5 Suggested pathways of GTS-21-mediated attenuation of HALI. In cells, including lung cells, HMGB1 shuttles between the nucleus and cytoplasm. Under room air, the rate of HMGB1 nuclear import exceeds that of re-diffusion plus export. Thus, HMGB1 appears predominantly or solely in the nucleus. The prolonged exposure to hyperoxia induces HMGB1 translocation from the nucleus to the cytoplasm. The a7nAChR agonist, GTS-21, inhibits hyperoxia-induced translocation and subsequent release of nuclear HMGB1, and its accumulation in the airways and the circulation. As a result, GTS-21 is efficacious in attenuating hyperoxia-induced infiltration of leukocytes, including neutrophils and inflammatory monocytes, into the airways, thereby significantly reducing hyperoxia-induced inflammatory lung injury

counts in the airways (Fig. 3a). However, there was a significant dose-dependent decrease in the infiltration of neutrophils (Fig. $3 \mathrm{~b}$ and c). Furthermore, the administration of $4 \mathrm{mg} / \mathrm{kg}$ i.p. of GTS-21 significantly decreased the infiltration of CD11 ${ }^{\text {low }}$ CD $11 b^{\text {hi }}$ monocytes into the airways $\left(1.71 \pm 0.52 \times 10^{4}\right.$ versus control vehicle $16.19 \pm$ $5.36 \times 10^{4} / \mathrm{ml}, p<0.05$, Fig. $3 \mathrm{~d}$ and e). Congruent with this finding, the levels of monocyte chemotactic protein1 (MCP-1), a proinflammatory cytokine involved in the recruitment of monocytes (Lim et al. 2015), were significantly increased in the airways of hyperoxic animals and this increase was significantly attenuated in mice treated with $4 \mathrm{mg} / \mathrm{kg}$ i.p. of GTS-21 ( $p<0.05$, Fig. 3f). Thus, these data suggest that the administration of GTS-21 attenuates HALI by decreasing the accumulation of airway HMGB1 and MCP-1, leading to a decrease in the infiltration of neutrophils and monocytes in the airways. These results are consistent with previous reports showing that $\alpha 7 \mathrm{nAChR}$ agonists such as nicotine, PNU282987 and DMAB-inhibit leukocyte infiltration in the lungs in mouse models of endotoxemia and E. coli pneumonia (Pavlov et al. 2007; Su et al. 2010).

The results shown in Fig. $1 \mathrm{~b}$ and $\mathrm{c}$ indicate that prolonged exposure to hyperoxia can significantly increase the lung injury score, which includes increased cellularization. To determine whether the increased lung injury score in hyperoxic mice results from an increase in the infiltration of macrophages into the lung tissue, lung tissues were immunolabelled for CD11b, a panmacrophage marker for both residential macrophages/ monocytes and those recruited (Misharin et al. 2013; Yu et al. 2016; Bronte et al. 2016). The results (Figs. 4a and b) indicated that hyperoxia significantly increased the macrophages/monocytes in lung tissues (Fig. 4a and b). Furthermore, GTS-21 significantly decreased the hyperoxia-induced $\mathrm{CD}_{11 \mathrm{~b}^{+}}$macrophage/monocyte infiltration in lung tissue $(21.9 \pm 3.0$ cells/field versus control vehicle $10.8 \pm 1.5$ cells/field, $p<0.05$; Fig. $4 \mathrm{a}$ and $\mathrm{b}$ ).

Decreasing the infiltration of circulating proinflammatory monocytes into the lung has been shown to play an important role in attenuating inflammatory lung diseases (Jiang et al. 2017; Wang et al. 2019; Zhang et al. 2018). It has been suggested that the increased expression of the Ly6C surface antigen can be used to define the inflammatory status of monocytes in the circulation and after tissue infiltration (Kratofil et al. 2017). To further assess whether the macrophages/ monocytes in hyperoxic mice are pro-inflammatory, the expression of Ly6C was determined in macrophages/ monocytes isolated from mouse serum and lung lavage fluids. Flow cytometric analysis of macrophages/monocytes in serum and BAL fluids from hyperoxia-exposed mice treated with $4 \mathrm{mg} / \mathrm{kg}$ i.p. of GTS-21 indicated a significant reduction in the accumulation of $\mathrm{CD}_{11} \mathrm{~b}^{+}$and 


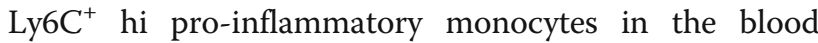
$\left(3.68 \pm 0.52 \times 10^{4}\right.$ versus control vehicle $6.33 \pm 1.05 \times$ $10^{4} / \mathrm{ml}, p<0.05$, Fig. 4c). However, the reduction of airway inflammatory macrophages/monocytes was not significant $\left(0.691 \pm 0.243 \times 10^{4}\right.$ versus control vehicle $0.891 \pm 0.173 \times 10^{4} / \mathrm{ml}$, Fig. $\left.4 \mathrm{~d}\right)$.

The activation of $\alpha 7 \mathrm{nAChR}$ can also inhibit endothelial cell activation, thus affecting leukocyte recruitment in acute inflammation (Saeed et al. 2005). It has been reported that the local activation of $\alpha 7 \mathrm{nAChR}$ in the lungs by the intra-tracheal administration of either nicotine (a non-selective agonist) or PNU-282987 (a selective $\alpha 7 \mathrm{nAChR}$ agonist) significantly attenuates the acidinduced increase in lung permeability and edema, and the protective effect of nicotine is abolished by methyllycaconitine (MLA), an antagonist of $\alpha 7 \mathrm{nAChR}$ (Su et al. 2007). It should be noted that the protective effects of GTS-21 treatment may be due, in part, to its effect on non- $\alpha 7 \mathrm{nAChR}$ cellular targets that produce antiinflammatory efficacy. For example, in LPS-stimulated primary $\alpha 7 n A C h R$ knockout macrophages, GTS-21 suppressed TNF $\alpha$ and IL-6 secretion (Garg and Loring 2019). Regardless of whether GTS-21 is functioning through $\alpha 7 \mathrm{nAChR}$ or other receptor-mediated pathways, the results presented in this study reveal that GTS-21 has protective efficacy for HALI by attenuating several markers of inflammation (Fig. 5). Thus, this study indicates that GTS-21, an $\alpha 7 \mathrm{nAChR}$ partial agonist, can significantly attenuate HALI by modulating the inflammatory response induced by hyperoxia.

\section{Conclusions}

To our knowledge, this study is the first to report that the systemic administration of GTS-21 decreases hyperoxiainduced acute inflammatory lung injury. The development of HALI is due, in part, to the accumulation of extracellular HMGB1 in the airways and the circulation. GTS-21 significantly decreases the hyperoxia-induced release of HMGB1 from hyperoxia-compromised lung cells into the airways and the circulation. This, in turn, can effectively attenuate hyperoxia-induced infiltration of inflammatory neutrophils and monocytes. Therefore, targeting pathways that block the accumulation of extracellular HMGB1 by GTS-21 may provide a novel approach for developing therapies to treat oxidative stress-induced inflammatory lung injury in patients on oxygen therapy. Moreover, these findings are especially pertinent in light of the requirement for prolonged ventilation in severe cases of COVID-19.

\section{Abbreviations}

a7nAChR: Alpha 7 nicotinic acetylcholine receptor; BAL: Bronchoalveolar lavage; GTS-21: [3-(2,4 dimethoxy- benzylidene)-anabaseine dihydrochloride]; HALI: Hyperoxia induced acute lung injury; HMGB1: High mobility group box protein 1: Hyperoxia: Greater than 99\% oxygen; LPS: Lipopolysaccharide; MCP-1: Monocyte chemoattractant protein-1; PA: Pseudomonas aeruginosa;
PMN: Polymorphonuclear cells; RA: Room air (21\% Oxygen); RAGE: Receptor for advanced glycation end-product; TNF: Tumor necrosis factor

\section{Consent for publications}

All authors read and approved the manuscript.

\section{Authors' contributions}

$R S, L L M, A G, M L$, and SVF designed and performed experiments. RS, AG, ML, and LLM analyzed data. SVF provided technical expertise in flow cytometry. RS, AG, SVF, ML, MW, ATM, VAP, JCP, CRA, KJT, and LLM conceived the project and wrote the paper. All authors read and approved the final manuscript.

\section{Funding}

This study was funded by Grants from The National Heart and Blood Institute (HL093708, to LLM) and intramural grants from St. John's University (to LLM).

\section{Availability of data and materials}

The datasets used and/or analyzed during the current study are available from the corresponding author on reasonable request.

Ethics approval and consent to participate

The study was reviewed and approved by the IACUC at St. John's University.

\section{Competing interests}

The authors have no competing interests to declare.

Received: 4 November 2019 Accepted: 29 April 2020

Published online: 29 June 2020

\section{References}

Abraham E, Arcaroli J, Carmody A, Wang H, Tracey KJ. Cutting edge: HMG-1 as a mediator of acute lung inflammation. J Immunol. 2000;165(6):2950: 248-51.

Andersson U, Tracey KJ. HMGB1 is a therapeutic target for sterile inflammation and infection. Annu Rev Immunol. 2011;29:139-62.

Andersson U, Wang H, Palmblad K, Aveberger AC, Bloom O, Erlandsson-Harris $\mathrm{H}_{\text {, }}$ et al. High mobility group 1 protein (HMG-1) stimulates proinflammatory cytokine synthesis in human monocytes. J Exp Med. 2000;192(4):565-70.

Barnett N, Ware LB. Biomarkers in acute lung injury - marking forward Progress. Crit Care Clin. 2011 Jul;27(3):661-83.

Belperio JA, Keane MP, Burdick MD, Londhe V, Xue YY, Li K, et al. Critical role for CXCR2 and CXCR2 ligands during the pathogenesis of ventilator-induced lung injury. J Clin Invest. 2002;110(11):1703-16.

Bhandari V, Elias JA. Cytokines in tolerance to hyperoxia-induced injury in the developing and adult lung. Free Radic Biol Med. 2006:41(1):4-18.

Bonaldi T, Talamo F, Scaffidi P, Ferrera D, Porto A, Bachi A, et al. Monocytic cells hyperacetylate chromatin protein $\mathrm{HMGB} 1$ to redirect it towards secretion. EMBO J. 2003;22(20):5551-60,

Borovikova LV, Ivanova S, Zhang M, Yang H, Botchkina Gl, Watkins LR, et al. Vagus nerve stimulation attenuates the systemic inflammatory response to endotoxin. Nature. 2000:405(6785):458-62.

Brewer SC, Wunderink RG, Jones CB, Leeper KV. Ventilator-associated pneumonia due to Pseudomonas aeruginosa. Chest. 1996;109(4):1019.

Bronte V, Brandau S, Chen S-H, Colombo MP, Frey AB, Greten TF, et al. Recommendations for myeloid-derived suppressor cell nomenclature and characterization standards. Nat Commun. 2016;7(1):1-10.

Bustin M. Revised nomenclature for high mobility group (HMG) chromosomal proteins. Trends Biochem Sci. 2001;26(3):152-3.

Calogero S, Grassi F, Aguzzi A, Voigtlander T, Ferrier P, Ferrari S, et al. The lack of chromosomal protein $\mathrm{Hmg} 1$ does not disrupt cell growth but causes lethal hypoglycaemia in newborn mice. Nat Genet. 1999;22(3):276-80.

Carvalho CR. de Paula pinto Schettino G, Maranhao B, Bethlem EP. Hyperoxia and lung disease. Curr Opin Pulm Med. 1998:4(5):300-4.

Chastre J, Fagon JY. Ventilator-associated pneumonia. Am J Respir Crit Care Med. 2002;165(7):867.

Cook DJ, Walter SD, Cook RJ, Griffith LE, Guyatt GH, Leasa D, et al. Incidence of and risk factors for ventilator-associated pneumonia in critically ill patients. Ann Intern Med. 1998;129(6):433-40.

Crapo JD. Morphologic changes in pulmonary oxygen toxicity. Annu Rev Physiol. 1986;48:721-31. 
Crapo JD, Barry BE, Gehr P, Bachofen M, Weibel ER. Cell number and cell characteristics of the Normal human lung 1-3. Am Rev Respir Dis. 1982; 126(2):332-7.

de Jonge WJ, Ulloa L. The alpha7 nicotinic acetylcholine receptor as a pharmacological target for inflammation. Br J Pharmacol. 2007;151(7):915.

Doerschuk CM. Leukocyte trafficking in alveoli and airway passages. Respir Res. 2000;1(3):136-40.

Entezari M, Javdan M, Antoine DJ, Morrow DMP, Sitapara RA, Patel V, et al. Inhibition of extracellular HMGB1 attenuates Hyperoxia-induced inflammatory acute lung injury. Redox Biol. 2014; 2: 314-322.

Entezari M, Weiss DJ, Sitapara R, Whittaker L, Wargo MJ, Li J, et al. Inhibition of high-mobility group box 1 protein (HMGB1) enhances bacterial clearance and protects against Pseudomonas aeruginosa pneumonia in cystic fibrosis. Mol Med. 2012;18(1):477.

Garg BK, Loring RH. GTS-21 has cell-specific anti-inflammatory effects independent of a7 nicotinic acetylcholine receptors. PLoS One. 2019;14(4): e0214942.

Giwa AL, Desai A, Duca A. Novel 2019 coronavirus SARS-CoV-2 (COVID-19): An updated overview for emergency clinicians. Emerg Med Pract. 2020; 22(5):1-28.

Grommes J, Soehnlein O. Contribution of neutrophils to acute lung injury. Mol Med (Cambridge, Mass). 2011;17(3-4):293-307.

Guan W, Ni Z, Hu Y, Liang W, Ou C, He J, et al. Clinical Characteristics of Coronavirus Disease 2019 in China. N Engl J Med. 2020;382(18): 1708-1720.

Han CH, Guan ZB, Zhang PX, Fang HL, Li L, Zhang HM, et al. Oxidative stress induced necroptosis activation is involved in the pathogenesis of hyperoxic acute lung injury. Biochem Biophys Res Commun. 2018;495(3):2178-83.

Han S, Mallampalli RK. The acute respiratory distress syndrome: from mechanism to translation. J Immunol. 2015;194(3):855-60.

Huang C, Wang Y, Li X, Ren L, Zhao J, Hu Y, et al. Clinical features of patients infected with 2019 novel coronavirus in Wuhan, China. Lancet. 2020; 395(10223):497-506.

Jiang Z, Zhou Q, Gu C, Li D, Zhu L. Depletion of circulating monocytes suppresses IL-17 and HMGB1 expression in mice with LPS-induced acute lung injury. Am J Physiol Lung Cell Mol Physiol. 2017;312(2):L231-42.

Kallet RH, Matthay MA. Hyperoxic acute lung injury. Respir Care. 2013;58(1):123-41.

Kang R, Chen R, Zhang Q, Hou W, Wu S, Cao L, et al. HMGB1 in health and disease. Mol Asp Med. 2014;40:1-116.

Kitagawa H, Takenouchi T, Azuma R, Wesnes KA, Kramer WG, Clody DE, et al. Safety, pharmacokinetics, and effects on cognitive function of multiple doses of GTS-21 in healthy. Male Volunteers Neuropsychopharmacology. 2003;28(3):542-51.

Kolliputi N, Shaik RS, Waxman AB. The inflammasome mediates hyperoxiainduced alveolar cell permeability. J Immunol (Baltimore, Md: 1950). 2010; 184(10):5819-26.

Kox M, Pompe JC, Peters E, Vaneker M, van der Laak JW, van der Hoeven JG, et al. alpha7 nicotinic acetylcholine receptor agonist GTS-21 attenuates ventilator-induced tumour necrosis factor-alpha production and lung injury. $\mathrm{Br}$ J Anaesth. 2011;107(4):559-66.

Kratofil RM, Kubes P, Deniset JF. Monocyte conversion during inflammation and injury. Arterioscler Thromb Vasc Biol. 2017;37(1):35-42.

Lim JP, Leung BP, Ding YY, Tay L, Ismail NH, Yeo A, et al. Monocyte chemoattractant protein-1: a proinflammatory cytokine elevated in sarcopenic obesity. Clin Interv Aging. 2015;10:605-9.

Liu G, Wang J, Park Y-J, Tsuruta Y, Lorne EF, Zhao X, et al. High mobility group protein-1 inhibits phagocytosis of apoptotic neutrophils through binding to phosphatidylserine. J Immunol. 2008;181(6):4240-6.

Lutz W, Stetkiewicz J. High mobility group box 1 protein as a late-acting mediator of acute lung inflammation. Int J Occup Med Environ Health. 2004; 17(2):245-54

Martino AT, Suzuki M, Markusic DM, Zolotukhin I, Ryals RC, Moghimi B, et al. The genome of self-complementary adeno-associated viral vectors increases tolllike receptor 9-dependent innate immune responses in the liver. Blood. 2011; 117(24):6459-68.

Matthay MA, Ware LB, Zimmerman GA. The acute respiratory distress syndrome. J Clin Invest. 2012;122(8):2731-40

Matthay MA, Zimmerman GA. Acute lung injury and the acute respiratory distress syndrome: four decades of inquiry into pathogenesis and rational management. Am J Respir Cell Mol Biol. 2005;33(4):319-27.

Mavropoulos SA, Khan NS, Levy ACJ, Faliks BT, Sison CP, Pavlov VA, et al. Nicotinic acetylcholine receptor-mediated protection of the rat heart exposed to ischemia reperfusion. Mol Med. 2017;23(1):120-33.
Misharin AV, Morales-Nebreda L, Mutlu GM, Budinger GRS, Perlman H. Flow cytometric analysis of macrophages and dendritic cell subsets in the mouse lung. Am J Respir Cell Mol Biol. 2013;49(4):503-10.

Mokra D, Kosutova P. Biomarkers in acute lung injury. Respir Physiol Neurobiol. 2015 Apr;209:52-8.

Morrow DMP, Entezari-Zaher T, Romashko J III, Azghani AO, Javdan M, Ulloa L, et al. Antioxidants preserve macrophage phagocytosis of Pseudomonas aeruginosa during hyperoxia. Free Radic Biol Med. 2007;42(9):1338-49.

Ogawa EN, Ishizaka A, Tasaka S, Koh H, Ueno H, Amaya F, et al. Contribution of high-mobility group box-1 to the development of ventilator-induced lung injury. Am J Respir Crit Care Med. 2006;174(4):400-7.

Olson TS, Ley K. Chemokines and chemokine receptors in leukocyte trafficking. Am J Phys Regul Integr Comp Phys. 2002;283(1):R7-28.

Patel VS, Sitapara RA, Gore A, Phan B, Sharma L, Sampat V, et al. High mobility group box-1 mediates Hyperoxia-induced impairment of Pseudomonas aeruginosa clearance and inflammatory lung injury in mice. Am J Respir Cell Mol Biol. 2013;48(3):280-7.

Pavlov VA, Ochani M, Yang LH, Gallowitsch-Puerta M, Ochani K, Lin X, et al. Selective [alpha] 7-nicotinic acetylcholine receptor agonist GTS-21 improves survival in murine endotoxemia and severe sepsis*. Crit Care Med. 2007:35(4):1139.

Pittet JF, Mackersie RC, Martin TR, Matthay MA. Biological markers of acute lung injury: prognostic and pathogenetic significance. Am J Respir Crit Care Med. 1997;155(4):1187-205

Rosas-Ballina M, Goldstein RS, Gallowitsch-Puerta M, Yang L, Valdés-Ferrer SI, Patel NB, et al. The selective a7 agonist GTS-21 attenuates cytokine production in human whole blood and human monocytes activated by ligands for TLR2, TLR3, TLR4, TLR9, and RAGE. Mol Med. 2009;15(7-8):195.

Saeed RW, Varma S, Peng-Nemeroff T, Sherry B, Balakhaneh D, Huston J, et al. Cholinergic stimulation blocks endothelial cell activation and leukocyte recruitment during inflammation. J Exp Med. 2005;201(7):1113-23.

Scaffidi $P$, Misteli T, Bianchi ME. Release of chromatin protein HMGB1 by necrotic cells triggers inflammation. Nature. 2002;418(6894):191-5.

Silversides JA, Ferguson ND. Clinical review: acute respiratory distress syndrome clinical ventilator management and adjunct therapy. Crit Care. 2013;17(2):225.

Sitapara RA, Antoine DJ, Sharma L, Patel VS, Ashby CR Jr, Gorasiya S, et al. The alpha7 nicotinic acetylcholine receptor agonist GTS-21 improves bacterial clearance in mice by restoring hyperoxia-compromised macrophage function. Mol Med (Cambridge, Mass). 2014;20(1):238-47.

Slutsky AS. Lung injury caused by mechanical ventilation. Chest. 1999:116(1 Suppl):9S-15S.

Snider GL, Rinaldo JE. Oxygen therapy, oxygen therapy in medical patients hospitalized outside of the intensive care unit. Am Rev Respir Dis. 1980;122(5 Pt 2):29-36.

Steer JH, Mann TS, Lo SZY, Inglis JJ, Yap HS, Henry PJ, et al. Early induction of uncoupling protein-2 in pulmonary macrophages in hyperoxia-associated lung injury. Inhal Toxicol. 2013;25(9):544-52.

Su X, Lee JW, Matthay ZA, Mednick G, Uchida T, Fang X, et al. Activation of the a7 $n A C h R$ reduces acid-induced acute lung injury in mice and rats. Am J Respir Cell Mol Biol. 2007;37(2):186-92.

Su X, Matthay MA, Malik AB. Requisite role of the cholinergic alpha7 nicotinic acetylcholine receptor pathway in suppressing Gram-negative sepsis-induced acute lung inflammatory injury. J Immunol (Baltimore, Md: 1950). 2010;184(1): 401-10..

Swirski FK, Nahrendorf M, Etzrodt M, Wildgruber M, Cortez-Retamozo V, Panizzi P et al. Identification of splenic reservoir monocytes and their deployment to inflammatory sites. Science. 2009;325(5940):612-6.

Szarka RJ, Wang N, Gordon L, Nation PN, Smith RH. A murine model of pulmonary damage induced by lipopolysaccharide via intranasal instillation. J Immunol Methods. 1997;202(1):49-57.

Taniguchi N, Kawahara Kl, Yone K, Hashiguchi T, Yamakuchi M, Goto M, et al. High mobility group box chromosomal protein 1 plays a role in the pathogenesis of rheumatoid arthritis as a novel cytokine. Arthritis \& Rheumatism. 2003:48(4):971-81.

Tarnawski L, Reardon C, Caravaca AS, Rosas-Ballina M, Tusche MW, Drake AR, et al. Adenylyl Cyclase 6 mediates inhibition of TNF in the inflammatory reflex. Front Immunol. 2018;9:2648.

Ueno H, Matsuda T, Hashimoto S, Amaya F, Kitamura Y, Tanaka M, et al. Contributions of high mobility group box protein in experimental and clinical acute lung injury. Am J Respir Critical Care Med. 2004:2004021880 Cv1. 
Valdés-Ferrer SI, Rosas-Ballina M, Olofsson PS, Lu B, Dancho ME, Ochani M, et al. Expression of concern: HMGB1 mediates splenomegaly and expansion of splenic CD11b+ Ly-6Chigh inflammatory monocytes in murine sepsis survivors. J Intern Med. 2013;274(4):381-90.

van Zoelen MA, Ishizaka A, Wolthuls EK, Choi G, van der Poll T, Schultz MJ. Pulmonary levels of high-mobility group box 1 during mechanical ventilation and ventilator-associated pneumonia. Shock (Augusta, Ga). 2008:29(4):441-5.

Wang $\mathrm{H}$, Bloom O, Zhang M, Vishnubhakat JM, Ombrellino M, Che J, et al. HMG-1 as a late mediator of endotoxin lethality in mice. Science (New York, NY). 1999;285(5425):248-51.

Wang $H$, Liao H, Ochani M, Justiniani M, Lin X, Yang L, et al. Cholinergic agonists inhibit HMGB1 release and improve survival in experimental sepsis. Nat Med. 2004;10(11):1216-21.

Wang H, Yu M, Ochani M, Amella CA, Tanovic M, Susarla S, et al. Nicotinic acetylcholine receptor alpha7 subunit is an essential regulator of inflammation. Nature. 2003:421(6921):384-8.

Wang M, Gauthier A, Daley L, Dial K, Wu J, Woo J, et al. Nuclear damage associated molecular pattern (DAMP) molecule HMGB1 in the pathogenesis of lung diseases. Antioxid Redox Signal. 2019;31(13): 954-993.

Windhorst C, Harth R, Wagoner C. Patients Requiring Tracheostomy and Mechanical Ventilation. The ASHA Leader. 2009. https://doi.org/10.1044/ leader.FTR1.14012009.10 ss.

Xie K, Yu Y, Huang Y, Zheng L, Li J, Chen H, et al. Molecular hydrogen ameliorates lipopolysaccharide-induced acute lung injury in mice through reducing inflammation and apoptosis. Shock (Augusta, Ga). 2012;37(5):548-55.

Yang H, Liu H, Zeng Q, Imperato GH, Addorisio ME, Li J, et al. Inhibition of HMGB1/RAGE-mediated endocytosis by HMGB1 antagonist box A, antiHMGB1 antibodies, and cholinergic agonists suppresses inflammation. Mol Med. 2019;25(1):-13.

Yang H, Wang H, Tracey KJ. HMG-1 rediscovered as a cytokine. Shock (Augusta, Ga). 2001;15(4):247-53.

Yu Y-RA, O'Koren EG, Hotten DF, Kan MJ, Kopin D, Nelson ER, et al. A Protocol for the Comprehensive Flow Cytometric Analysis of Immune Cells in Normal and Inflamed Murine Non-Lymphoid Tissues. PLoS One. 2016;11(3): e0150606.

Zhang L, Wang Y, Wu G, Xiong W, Gu W, Wang C-Y. Macrophages: friend or foe in idiopathic pulmonary fibrosis? Respir Res. 2018;19(1): 170.

Zhang X, Shan P, Sasidhar M, Chupp GL, Flavell RA, Choi AMK, et al. Reactive oxygen species and extracellular signal-regulated kinase 1/2 mitogenactivated protein kinase mediate hyperoxia-induced cell death in lung epithelium. Am J Respir Cell Mol Biol. 2003;28(3):305-15.

\section{Publisher's Note}

Springer Nature remains neutral with regard to jurisdictional claims in published maps and institutional affiliations.

Ready to submit your research? Choose BMC and benefit from:

- fast, convenient online submission

- thorough peer review by experienced researchers in your field

- rapid publication on acceptance

- support for research data, including large and complex data types

- gold Open Access which fosters wider collaboration and increased citations

- maximum visibility for your research: over $100 \mathrm{M}$ website views per year

At BMC, research is always in progress.

Learn more biomedcentral.com/submissions 